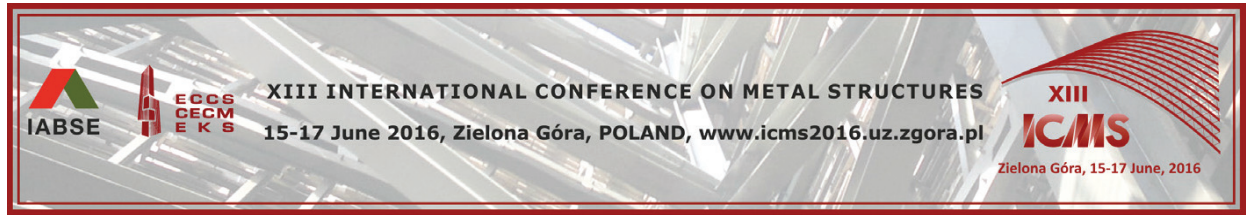

\title{
XIII International Conference on METAL STRUCTURES ICMS'2016
}

Organized by:

\section{Section of Metal Structures}

of the Committee for Civil Engineering of the Polish Academy of Sciences (SMS CCE PAS)

University of Zielona Góra, Faculty of Civil and Environmental Engineering, Institute of Building Engineering

Under auspices of:

\section{Committee for Civil Engineering of Polish Academy of Sciences}

Polish Chamber of Steelworks

Polish Chamber of Civil Engineers

Polish Association of Civil Engineers and Technicians University of Zielona Góra

and

European Convention for Constructional Steelwork International Association of Bridge and Structural Engineering

will be held on 15-17 of June 2016 in Zielona Gora, POLAND. It is a continuation of the tradition of metal structures conferences which have been organized in Poland since 1958. The last four conferences were organized in Cracow (1995), Gdańsk (2001), Rzeszów (2006) and Wrocław (2011).

The conference will address recent development in steel, steel-concrete composite and aluminium structures, and will be focusing on the implementation of Eurocodes. The Conference will be attended and addressed by worldwide known researchers and experts.

Advanced methods of analysis

Structural stability

Fabrication and erection

High strength and stainless steel

Plated and shell structures

Tanks and silos

Pipelines

Flexible soil-steel structures

Connections

Cold-formed elements and structures

Composite structures

Cable and membrane structures

Prestressed metal structures
Main topics:

Seismic-resistant structures

Bridges and footbridges

Tall buildings

Fire resistance

Robustness

Refurbishment

Sustainability

Fatigue and durability

Steel and architecture

Light cladding, covering and facades

Innovative structures

Design recommendations, codification

More details about the conference are available on the conference WebSite: 